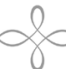

\title{
Territorialidades étnicas e identidade nacional: o caso da Guiana Francesa ${ }^{1}$
}

Charles Benedito Gemaque

Souza*

\begin{abstract}
Resumo: A Guiana Francesa é uma região administrativa da França na Pan-Amazônia, caracterizada pelo encontro e desencontro de etnias as quais são uma expressão dessa sociedade pós-colonial e, como tal, revela as contradições inscritas nas representações e nos territórios, bem como nas estratégias de poder elaboradas pelo choque entre as diferenças. Diante disso, a memória coletiva é marcada pelo antigo padrão dominado e dominante, sendo que no caso da Guiana Francesa, criou-se um sistema complexo e plural de resistência, estigmas, adaptação e simbiose de etnicidades, repercutindo na configuração urbana de suas principais cidades. Em conseqüência, a busca atual pela afirmação de uma identidade guianesa simboliza mais do que um projeto de nacionalidade, trata-se de uma resposta ao processo de inferiorização que somatizou e descrimina os descendentes de escravos e os "guianeses" de modo geral.
\end{abstract}

\section{Territoires ethniques et identité nacional: le cas de la Guyane Française}

Resumé: La Guyane française est une région administrative de la France dans le Pan-Amazonie, caractérisée par la rencontre et choc des groupes ethniques qui sont une expression de la société post-coloniale et en tant que telle, révèle les contradictions dans les représentations et entrés sur le territoire, ainsi que des stratégies puissance produite par la collision entre les différences. Dans ce contexte, la mémoire collective est marquée par l'ancien modèle dominé et dominant, et dans le cas de la Guyane, il a créé un système complexe de résistance, des stigmatisme, d'adaptation et de symbiose de pluriels ethnies, ce qui reflète le contexte urbain de ses grandes villes. En conséquence, la recherche actuelle d'affirmation d'une identité guyanaise symbolise plus que d'un projet de nationalité, il est une réponse à la procédure dégradant et de discrimination submis aux descendants d'esclaves et les «Guyanais» en général.
* Doutorando em Desenvolvimento Socioambiental do Programa de Pós-Graduação interdisciplinar do Núcleo de Altos Estudos Amazônicos- NAEA, que é vinculada a Universidade Federal do Pará-UFPA

Palavras-chave: Etnias, territórios, nacionalidade, Pan-Amazônia.

Mots-clés: Ethnies, Territoires, nationalité, PanAmazonie.

1 Pesquisa realizada com 0 apoio do Conselho Nacional de Desenvolvimento Cientifico e Tecnológico-CNPq. Este artigo é parte integrante da tese "Conflitos e identidades étnicas na Pan-Amazônia : os territórios étnicos da cidade de KourouGuiana Francesa" apresentado ao Núcleo de Altos Estudos Amazônicos (UFPA). 


\section{Introdução}

A Guiana Francesa é a única possessão francesa situado oficialmente na América do Sul. Os limites territoriais são delimitados: ao norte pelo oceano Atlântico, ao oeste pelo rio Maroni, ao sul pelos montes Tumuc-Humac, e à leste com o rio Oiapoque, cujos $600 \mathrm{Km}$ separam a Guiana Francesa do Brasil edificando a mais longa fronteira do Estado francês com uma nação estrangeira.

Ressalta-se que a ideologia francesa ainda reproduz o antigo sistema de dominação política, cultural e econômica por meio do controle das relações internas e externas da Guiana Francesa. Tendo como alicerce um processo de aculturação "pós-colonial", distanciada da realidade imediata, em conseqüência a integração dentro da sociedade guianesa passa necessariamente pela assimilação de normas e valores ditos "universais" historicamente definidas pelo Estado francês.

Uma das conseqüências desse processo de assimilação foi à difusão de estigmas e de todo tipo de descriminações, que dificultam qualquer estratégia de coexistência social. Em virtude disso, as diversas formas de distúrbios identitarios começam a fazer parte das praticas sócio-espaciais da Guiana Francesa, criando ressentimentos mútuos e uma disposição de resistir por meio de sua organização sócio-espacial, língua e traços simbólicos.

Contudo, esse sentimento também é ambíguo diante de elementos que se alternam e se sobrepõem por um campo de força simbólica. As diferenças são cada vez mais invadidas por uma representação abstrata ligada à modernidade, à racionalidade voltada para o capital e a mobilidade sócio-econômica pode levar a uma estratificação inter-étnica. Deste modo, a sobreposição das individualidades dentro dos grupos étnicos significa aceitar o processo de assimilação das regras e normas universalistas.

Para materializar esse trabalho tornou-se imprescindível optar por métodos de interpretação e técnicas de pesquisa que expressassem a complexidade da espacialidade étnica e afirmação da nacionalidade da Guiana Francesa. Para tanto, a abordagem aqui proposta partiu da analise documental e da observação etnológica das posições, das redes e dos itinerários realizados pelos diferentes grupos étnicos. Além disso, houve um acompanhamento de documentos, paginas virtuais, programas de radiodifusão voltados para algumas das etnias presentes na Região.

A sistematização desses dados qualitativos necessariamente teve critérios flexíveis de acordo com os objetivos previamente delimitados para o artigo, o que não significou a subjetivação do estudo. Por outro lado, é preciso assinalar as dificuldades que ocorreram durante o período de investigação: o domínio das línguas; os mecanismos de aproximação; a conformação de uma rede de colaboradores e informantes; os arranjos logísticos; e o tempo disponível. Por fim, não é possivel não comentar as inúmeras dificuldades impostas para transposição da fronteira, entre 0 Brasil e a Guiana Francesa concretamente esse foi o maior obstáculo para a finalização dessa pesquisa.

\section{O processo de formação sócio-espacial da Guiana Francesa}

A colônia da Guiana Francesa em muitos aspectos (políticos e sociais) assemelhava-se ao modelo imposto nas Antilhas francesas (Guadalupe, Martinica e Haiti), porém havia um grande diferencial, a imensidão das florestas e rios locais que era o exemplo da Amazônia portuguesa. No

Geografia Ensino \& Pesquisa, v. 16, n.2 p. 7 - 22, maio/ago. 2012

Territorialidades étnicas e identidade nacional: o caso da Guiana Francesa

8

ISSN 2236-4994 entanto, os fracassos econômicos e de povoamento e as constantes transformações no projeto colonialista na Guiana se devem mais as fatores históricos do que a dificuldade com o meio ambiente.

A estratégia de ocupação do espaço guianês seguiu inicialmente à organização territorial das populações indígenas diante do ecossistema e de suas técnicas de sobrevivência. Nestes termos, as aldeias surgiam e desapareciam ao longo de caminhos e rios sendo delimitadas e 
reconhecidas por identificações toponímicas e simbólicas de cada etnia. 0 modo de produção da maioria dos grupos era itinerante, o que restringia ainda mais o adensamento populacional e que, ao mesmo tempo, impetrava o controle de um território vasto (MAM LAM FOUCK, 2002, p. 20).

$\mathrm{O}$ inicio do processo da exploração colonial da Guiana Francesa se deu no século XVII, durante o período das grandes navegações, com a chegada da primeira expedição comandada por La Ravardière, o mesmo que fundou a cidade de São Luis, no Estado do Maranhão. 0 projeto de colonização comercial da possessão baseava-se no modelo denominado habitation (Cardoso, 1999, p. 61), entretanto, a região foi historicamente marginalizada dentro da estratégia imperialista da França.

$\mathrm{Na}$ época, Espanha e Portugal por meio do tratado de Tordesilhas já tinham estabelecidos os limites de seus domínios no continente sul-americano. Ora as "Guianas" era a região menos controlada dentro desses dois impérios, o que permitiu o advento tardio ao continente de ingleses, holandeses e franceses, que vinham progressivamente se estabelecendo em importantes áreas das Antilhas e da América do Norte, logo a Guiana foi conquistada mais em conseqüência de uma questão política e ideológica da França em relação aos outros impérios europeus do que pelo interesse especifico na região.

Surge então, uma questão fundamental para a consolidação da soberania francesa e delimitação de fronteiras, a "fraca densidade populacional". Tal carência demográfica torna-se a partir desse momento um discurso constante na historia da Guiana Francesa, para Mam Lam Fouck (2002) isso explica grande parte da contradição, que perdura até hoje, entre os interesses geopolíticos da "metrópole" e o espaço colonial efetivamente ocupado pelos franceses. Com isso, o fluxo migratório tornou-se uma condição si que non para o sucesso de qualquer empreendimento econômico na região.

A monarquia francesa então busca reforçar o sistema colonial por meio da intensificação do trafego negreiro e por conseqüência do escravismo como estratégia de ocupação populacional e de incentivo ao desenvolvimento da produção mercantil na região. Contudo, a falta de continuidade nessa política e as circunstâncias históricas que cercam a Guiana Francesa, guerras e, sobretudo as maus sucedidas experiências de colonização durante o século XVII, enquanto as Antilhas tornavamse um centro comercial importante e em expansão, criaram barreiras sérias a essa pretensão.

Nesse contexto, a Guiana Francesa tornou-se um caso singular diante de formações socioeconômicas significativas do escravismo colonial nas Américas. Embora a base da sociedade guianense no início do século XVIII fosse escravocrata, em comparação com as Antilhas francesas, a quantidade de escravos negros era anódino devido às dificuldades de se estabelecer empreendimentos sustentáveis na região.

Diante do custo do trafego negreiro e os problemas financeiros dos colonos locais houve tentativas de se escravizar os povos indígenas da região, porém o alto índice de mortalidade devido aos maus tratos físicos e psicológicos, o choque cultural e as fugas constantes tornaram essa alternativa inviável. Ademais, a igreja católica condenava a captura dos índios para esse tipo de trabalho forçado nas colônias, mesmo assim muitos foram capturados e vendidos, inclusive para as Antilhas.

Logo, a sociedade guianense do século XVIII era extremamente hierarquizada através de três características: a cor da pele (brancos, negros, índios e mestiços); a riqueza (número de terras cultivadas ou/e de escravos); e pelo status (nobres, trabalhadores livres, e escravos). A população masculina era muito maior, sobretudo entre os brancos e os negros, o que ocasionou uma série de relacionamentos não oficiais entre brancos e as mulheres escravas e indígenas. Tal fato ensejou um inegável acréscimo na taxa de natalidade de crianças mestiças, o que remeteu a uma perturbação na ordem estamental de cunho étnico dentro desta sociedade escravocrata estabelecida na Guiana Francesa, face ao número pequeno de colonos brancos.

Por outro lado, o aumento relativo de homens livres e de escravos negros diante de uma população "branca" cada vez menor continuou trazendo turbulências externas, mas, sobretudo internas à colônia. Autoridades religiosas e políticas locais condenavam a concubinagem e a

Geografia Ensino \& Pesquisa, v. 16, n.2 p. 7 - 22, maio/ago. 2012

Souza, C. B. G

ISSN 2236-4994 
mestiçagem crescente, tratando-as como uma "mancha perigosa" para a sociedade guianense do principio do século XIX. Segundo essa visão etnocêntrica, esses fenômenos só contribuíam para o aumento da indulgência colonial em relação ao contrabando, a corrupção e o aumento do número de indigentes.

Nesse período, o fenômeno da "marronage" começava a ganhar corpo na Guiana Francesa, embora geralmente os refugiados fossem oriundos do Suriname estes conseguiam desde início do século XVII constituir diversos grupos organizados e autônomos ao longo do rio Maroni. A presença dos Noirs Marrons (Negros da Floresta) na fronteira guianense causou posições controversas, para alguns se tratava de mais uma ameaça a sociedade e ao território, para outros poderia trazer um acréscimo de mão obra a um custo acessível. Price (2002) mostra que essa ambigüidade refletiu na política francesa, criando desacordos e incertezas de ambas às partes. 0 fato é que mesmo com uma estratégia que orbitava entre o rechaçamento e o acolhimento, estes se tornaram parte integrante da sociedade local.

Todavia, no começo do século XIX a França continuava a enfrentar o grande dilema de sua colônia sul-americana: como aumentar a ocupação do espaço e assim manter sua soberania territorial, sem que isso represente uma diminuição substancial de sua população "branca". Ora em 1815 em Viena as grandes potências européias se pronunciavam em favor da abolição do tráfego negreiro, condenando a antiga estratégia de ocupação da colônia. Com isso a resolução da questão demográfica tornou-se imperativa.

Segundo Mam Lam Fouck (2002, p. 55) em detrimento do interesse claro da França, durante todo regime escravista (1626-1848), de se estabelecer uma hierarquia étnico-social, a verdade é que os colonos (brancos) não conseguiram estabelecer um sistema fechado. Entre as razões pode-se inferir que a falta de interesse e de adaptação entre os "brancos", de um lado, e o grande processo de mestiçagem entre as etnias e as condições históricas-geograficas desfavoráveis, de outro. Nestes termos e diante das ameaças externas a questão imperiosa para o Estado passou então a ser a ocupação dos "vazios" da Guiana Francesa.

Culminando em meados do século XIX com mais um plano de colonização paradoxal e autodestrutivo (CORNUEL, 2003), o então imperador Luis Napoleão (Napoleão III) decretou a criação de diversos campos de presidiários dentro da Guiana Francesa, principalmente entre os rios Mana e o Maroni, dentro de uma lógica de ocupação e de desenvolvimento colonial que desta vez envolveria os condenados pelo império francês.

Conforme Cornuel (2003) a fundação de uma colônia penal, escamoteia uma intenção metropolitana de se livrar dos "indesejáveis", de ambos os lados do oceano, e ao mesmo tempo preencher os vácuos demográficos. Infelizmente, essa decisão imperial abandonou o bom senso e, acima de tudo, as lições deixadas pelas tentativas passadas. Nessa direção, 0 autor acima citado chama atenção sobre as implicações étnicas por trás desse "novo" empreendimento francês.

A falta de escrúpulos e o desprezo da metropole em relação à Guiana Francesa criaram uma sociedade colonial desmotivada, incrédula e corrompida, o que ocasionou um novo fracasso econômico. Mais do que isso, o "inferno" dos presídios abortou uma concepção de igualdade étnica que poderia mostrar outra face da Guiana Francesa. O fato é que os campos de prisioneiros existiram em terras guianenses por quase um século (1852-1946) cujas conseqüências vão repercutir ao longo do século $X X$, período no qual persistiram as estruturas (pós) coloniais, e as dificuldades socioeconômicas (Lézy, 2000).

A Guiana Francesa do inicio do século XX era orientada para a monoprodução de ouro,

Geografia Ensino \& Pesquisa, v. 16, n.2 p. 7 - 22, maio/ago. 2012

Territorialidades étnicas e identidade nacional: o caso da Guiana Francesa em conseqüência boa parte dos antigos colonos "brancos" das plantations foram embora. Com isso, a orpaillage (corrida do ouro) era comandada pelos mestiços e os primeiros descendentes dos escravos, o extrativismo era feita de maneira tradicional e sem grande capitais envolvidos. 0 declínio do ciclo do ouro, a partir de 1920, foi resultado dos limites desse sistema de exploração, baseado em técnicas rudimentares e no acesso livre, que culminou com a crise econômica após a segunda guerra mundial. 


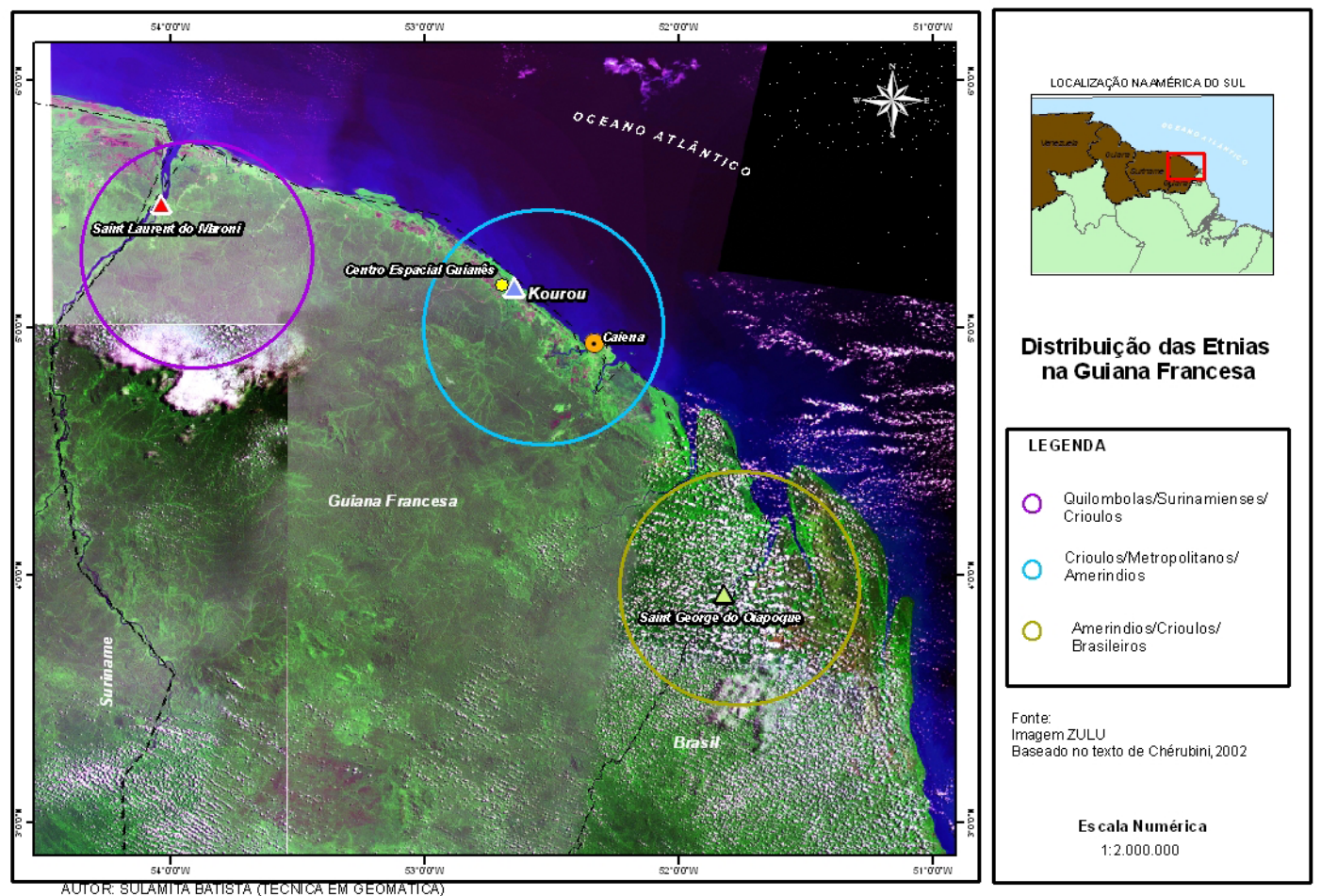

Em 1946, as antigas colônias francesas da Martinica, Guadalupe, Reunião e Guiana foram proclamadas Departamentos Ultramarinos (DOM) da França, entre elas a que apresentava o maior paradoxo entre a miséria social local e o nível de vida departamental era justamente a ex-colônia sul-americana, algo que a nova política francesa (pos) colonial não poderia admitir. 0 projeto de desenvolvimento para a Guiana Francesa visava então a afirmação de uma economia baseada na tradição produtiva colonial com a modernidade de novos equipamentos.

Deste modo, houve investimentos em telecomunicação, na rede de saneamento e de eletricidade ao mesmo tempo, criaram-se circuitos de crédito para a produção agropecuária, assim como o incentivo a mecanização da extração de minérios e uma política de desenvolvimento turístico. Apesar do salto qualitativo nas condições de vida, Mam Lam Fouck (2002, p. 110) indica que essa tentativa de transformar rapidamente uma região historicamente empobrecida em um prospero departamento francês esbarra na falta de novas atividades produtivas capazes de alavancar a economia local.

Ademais, a economia da Guiana Francesa era dominada pelo Estado, ou seja, o setor público era responsável por grande parte dos assalariados e dos investimentos, enquanto o privado se resumia aos pequenos comércios, a agricultura tradicional e pequenas empresas. A região tornou-se extremamente dependente dos recursos metropolitanos, criando um mundo à parte, onde o nível de vida se assemelha aos países do primeiro mundo contrastando com uma estagnação econômica própria dos países subdesenvolvidos.

De outro lado, com o fim da guerra da Argélia, a França precisava deslocar sua antiga base civil e militar de sua ex-possessão africana, e principalmente, encetar suas atividades espaciais. Por volta de 1964, o então presidente Charles de Gaulle, decide que a Guiana Francesa por sua posição geográfica privilegiada (próximo do equador) e com uma densidade populacional reduzida seria o local ideal para o novo centro espacial francês. Foi escolhida uma área de 300 kilometros quadrados às proximidades da então vila de Kourou. (600 habitantes).

Contudo, novamente o discurso sobre a carência de "mão-de-obra qualificada" para levantar a base física e a infra-estrutura urbana adequada vem a tona. Diante disso, a idéia de povoar a Guiana Francesa com atores sociais "capazes" de permitir o estabelecimento da empresa aeroespacial, assim os imigrantes tornaram-se parte de uma ideologia voltada para o desenvolvimento da região. Tal estado de espírito facilitou naquele momento a absorção do processo de imigração dentro da sociedade local.

Geografia Ensino \& Pesquisa, v. 16, n.2 p. 7 - 22, maio/ago. 2012

Souza, C. B. G

ISSN 2236-4994 
Nesse contexto, Calmont (2007) explana que o inicio da construção do Centro Espacial Guianês foi o estopim para segunda grande fase de imigração espontânea para a Guiana Francesa. As autoridades francesas incentivaram esse fluxo de mão de obra estrangeira, por intermédio de chamada em jornais, principalmente na Colômbia e no Brasil. Isso desencadeou um forte processo imigratório, atraindo trabalhadores de outros países vizinhos (Haiti, Suriname) tendo como ponto de atração os salários e o padrão "europeu". Em 1966 chegaram os primeiros imigrantes, os colombianos, que assinavam um termo de compromisso com a Secretaria Nacional de Imigração (ONI) de voltar ao seu país após os fins do trabalho, em pouco tempo estes foram sendo substituídos pelos brasileiros, seguidos dos caribenhos (Antilhas francesas e inglesas) e surinamienses. Jolivet (1986) mostra que o percentual de estrangeiros que trabalhava diretamente na construção da base física de Kourou suplantava os europeus e os crioulos.

Naquele momento, a construção do Centro Espacial Guianês (CSG) impulsionou a economia urbana de Kourou e a Guiana Francesa como um dos centros mais dinâmicos da Amazônia. Em conseqüência, tornou-se um ponto de atração para os imigrantes continentais devido à imagem de diversificação do seu mercado de trabalho. Porém, como o término da primeira fase do projeto nos anos 70 houve um arrefecimento dessa oferta de emprego, mesmo assim o fluxo migratório continuou crescente nos anos posteriores.

Embora faça parte de um conjunto administrativo único à sociedade da Guiana Francesa tem como particularidade o caráter plural devido à composição humana marcada pela presença de diversos grupos étnicos. Conforme Chalifoux (1992) é difícil definir se existe uma sociedade ou varias sociedades guianenses. Nesse sentido, podem-se distinguir vários grandes grupos étnicosociais na Guiana Francesa: os "ameríndios"; os Noirs Marrons; os crioulos; os metropolitanos; e os imigrantes.

Com uma população composta por 35\% imigrantes a Guiana Francesa apresenta uma heterogeneidade de traços comportamentais, estrutura familiar e notadamente de caráter lingüístico. Embora o francês seja a língua oficial e dominante, o crioulo é uma linguagem muito utilizada pelos moradores tanto dentro dos grupos étnicos autóctones, quanto no contato com os imigrantes.

Com uma área total de $83534 \mathrm{~km}^{2}$, representa cerca de $1 / 6$ de todo território francês, constitui-se na mais extensa região francesa. A população atual é de 199895 habitantes com uma densidade demográfica de 2,4 habitantes por $\mathrm{Km}^{2}$, uma das menores da França. A rede urbana da Guiana Francesa define-se a partir de três grandes conjuntos de cidades: as polaridades regionais (Caiena e Kourou); as cidades transfronteiriças (Saint Georges do Oiapoque e Saint Laurent do Maroni); e as pequenas comunidades isoladas.

Logo se infere o maior desafio para a afirmação da Guiana Francesa: consolidar uma autonomia político-econômica diante de grupos socio-étnicos autóctones e estrangeiros que se reconhecem, antes de tudo, como diferentes, situação que se reproduz tanto na região como no espaço intra-urbano de suas principais cidades (figura 1). Paradoxalmente, a busca histórica pelo povoamento da região é ao mesmo tempo considerada a solução e o grande problema.

Geografia Ensino \& Pesquisa, v. 16, n.2 p. 7 - 22, maio/ago. 2012

Territorialidades étnicas e identidade nacional: o caso da Guiana Francesa

\section{O Estado universalista e a dinâmica de afirmação da crioulidade}

Desde Revolução Francesa (1789) criou-se uma ideologia na qual a república teria como princípio valores universais: liberdade, fraternidade e igualdade entre os indivíduos no interior do território francês. Contudo, em nome desse universalismo republicano, a França estabeleceu um modelo de integração que não admitia as diferenças, baseando-se na assimilação dos valores (universais) da cultura francesa.

Nesse sentido, a tradição francesa impôs um processo de "miscigenação" que não reconheceu fronteiras nacionais e étnicas, o que significou grandes dificuldades identitárias tanto para os imigrantes que foram compelidos a abandonar suas referências, quanto para os autóctones 
que viram nessa política de assimilação uma intrusão na construção de sua sociedade (KOZAKAl; WOLTER, 2007). Mesmo assim, o universalismo republicano foi legitimado dentro das possessões francesas por leis que não resguardavam nenhuma espécie de minoria (étnica, religiosa), contrariando a idéia difundida fora da França.

A política de assimilação cultural nasce no final do século XIX, momento que a Illa republica francesa (1879-1940) busca homogeneizar seu corpo jurídico e o sistema educacional, e ao mesmo tempo, procura distancia-se da Igreja Católica e consolidar a expansão de sua economia. Progressivamente, porém, essa estratégia sofreu um processo de aculturação dentro das realidades coloniais, sendo fruto de uma negociação (manipulação) entre colonos e os povos autóctones. (BERNAND, 2001). Logo contrariando a legislação nacional, os costumes (hábitos, linguagens) locais foram tolerados nas colônias, criando por conseqüência contrapontos étnicos em relação ao universalismo francês.

As sociedades coloniais de fato conheceram uma mestiçagem dos elementos europeus com os dos africanos, indígenas entre outros, dando origem ao fenômeno da crioulidade. Price (2002) define a crioulidade como um "milagre" típico das Américas, onde o contato entre diversos grupos étnicos resultou em um complexo processo de construção e mudança de valores, saberes, crenças, simbologias e nomeadamente de linguagens dentro das sociedades autóctones. A origem do crioulo estaria na necessidade de sobrevivência e comunicação entre as diversas nações africanas trazidas como escravos para vários pontos do novo continente, desta forma estes produziram um dialeto comum colhendo termos de diversos idiomas.

Em território francês, a língua crioula (pidgin) nasceu dentro de um contexto de colonização européia, de chegada compulsória de africanos, de presença da população indígena e de uma grande serie de outros movimentos imigratórios ao longo dos anos. Para Arouck (2000) apesar das formações socio-espaciais diferenciadas, houve uma regionalização em termos de linguagens e por conseqüência, nos traços culturais, ou seja, a cultura crioula da Guiana Francesa é semelhante às manifestações crioulas nas Antilhas francesas e no Haiti.

Todavia, na Martinica e Guadalupe a identidade crioula foi o alicerce de um movimento de resistência as práticas universalistas, enquanto na Guiana Francesa esse fenômeno não se repetiu, o espaço crioulo era marginalizado (JOLIVET, 2000). A dispersão e isolamento das habitações e das diferenças, após o período de escravidão e, sobretudo, a polarização em torno da corrida do ouro (1855-1945) enfraqueceu a economia agrícola, e por conseqüência, o processo de fortalecimento de uma sociedade local.

Com isso os indivíduos assimilaram o sistema de classe, independentemente de sua etnicidade, com base primordialmente na estratificação social. Chérubini (2002) lembra que a modelagem da sociedade guianesa foi efetuada dentro de uma formação socioeconômica hierarquizada e ao mesmo tempo, aberta, na qual era possível casos de mestiçagem inclusive envolvendo grupos de estrangeiros, alguns considerados fechados (chineses), assim como a integração das novas gerações de imigrantes por meio da escolarização (aculturação pela língua), modos de vida, empregos e os lazeres.

Essa divisão social (étnica) acabou tendo uma estreita relação com o nível diferenciado de apropriação do universalismo francês. Conforme Jolivet (1986, p. 369) a existência de três camadas sociais (burguesa; intermediaria e sub-proletariados) é resultado direto desse processo, enquanto a burguesia é considerada "moderna" e totalmente integrada, normalmente são os metropolitanos e a elite crioula (caribenhos e nativos), os sub-proletariados tem outro nível de adaptação e por isso são rotulados de tradicionais. Já a classe intermediária se refere especificamente à maioria dos crioulos guianeses, assim como aos imigrantes amoldados a realidade imposta pelo processo de aculturação.

Jolivet (1982) acrescenta que a especificidade da crioulidade na Guiana Francesa abrange quatros aspectos inerente a sua trajetória: 1) a quase desaparição dos crioulos "brancos" a partir da segunda metade do século XIX, quando muitos colonos desistiram de suas habitations e regressaram para a metrópole; 2 ) a existência de grupos de Marrons oriundos do Suriname, que

Geografia Ensino \& Pesquisa, v. 16, n.2 p. 7 - 22, maio/ago. 2012

Souza, C. B. G

ISSN 2236-4994 
edificaram pequenos territórios com forte identificação africana; 3) a permanência de diferentes nações indígenas; 4) e a grande diversidade e renovação nos deslocamentos imigratórios.

A identidade crioula na Guiana Francesa caminhava, portanto, dentro de um emaranhado de manifestações (des) ordenadas, eternamente inconclusas e cada vez mais minoritárias. Diante disso, alguns intelectuais e políticos instituíram um projeto nacional que compreenderia além do créole as outras populações autóctones (indígenas e marrons). Criando um campo simbólico para reivindicar e fortalecer sua alteridade em relação aos outros grupos étnicos por meio da equivalência entre as três "raças" (AROUCK, 2000).

Para Hidair (2007) essas representações acabaram tendo um forte poder de exclusão social, uma vez que adotou apenas três grupos dentro de um emaranhado complexo e amplo de etnias. Mais do que isso, tais simbologias revelam uma ideologia que na pratica busca hierarquizar a cultura crioula diante dos outros dois grupos através da oposição moderno e tradicional. Deste modo, é possível afirmar que o sentir-se guianês, envolve disputas identitárias que se entrelaça com a luta por posição social, movimentos políticos e as fronteiras territoriais.

O discurso que construiu a identidade crioulo-guianesa nasceu dentro de um contexto de aculturação, na qual a tradição francesa era a base, por conseqüência os grupos autóctones "nãoassimilados" (ameríndios e marrons), sob o ponto de vista metropolitano, representavam um pólo negativo dessa crioulidade. Essa atribuição externa, para Colomb (1999), ecoou dentro da elite crioula que sempre viram no tradicionalismo desses grupos uma barreira para o progresso da sociedade guianesa.

No começo dos anos 80 do século passado, com o aumento demográfico dos grupos "não crioulos" devido à ampliação dos fluxos imigratórios, muda o papel político e social desempenhadas por essas etnias. As referências africanas e indígenas passam a ser (re) avaliadas diante da necessidade de construção de um projeto de referência regional face ao crescente pluralismo sociocultural. De outro lado, houve uma mobilização entorno da valorização da cultura crioula (língua, vestimentas) dentro do cotidiano local face às referências européias e caribenhas.

A crioulidade na Guiana Francesa tornou-se um sentimento de pertença reificado e conflituoso, para Arouck (2000: 97) isso alimentou entre os crioulos locais uma percepção de inferioridade em relação aos metropolitanos e aos crioulos caribenhos. Por isso, a cultura créole é muitas vezes restringida e/ou subjugada pelas manifestações culturais e esportivas externas, agravado pela constante emigração dos mais jovens para a metrópole. Logo, o crioulo é visto como um modo de vida alternativo, valido somente entre seus pares (privado) e em determinados espaços públicos.

Por sua vez, ameríndios e marrons não assumiram a identidade crioula, visto que para esses grupos trata-se de uma nova roupagem da política de assimilação e, por conseqüência, de marginalização dos seus costumes. De acordo com Colomb (1999) as experiências discriminatórias de integração ao conjunto da sociedade guianesa criaram movimentos de resistência como uma forte conotação étnica.

Ademais, houve uma segregação étnica legitimada dentro das possessões francesas, criando dois tipos de cidadãos, os de cidadania nacional, ou seja, os metropolitanos com plenos direitos e os "franceses" autóctones (mestiços, ameríndios e bushinenges) que tinham o direito de preservar suas tradições e religiões, mas, em compensação, eram privados da maioria dos direitos civis e de mobilização política. Em suma, esta exclusão instituiu o direito à diferença o que prevaleceu no período pós-colonial (após 1946), algo não previsto pela constituição francesa.

Em conseqüência, algumas etnias como os ameríndios da Guiana Francesa, por exemplo,

Geografia Ensino \& Pesquisa, v. 16, n.2 p. 7 - 22, maio/ago. 2012

Territorialidades étnicas e identidade nacional: o caso da Guiana Francesa foram divididos pelo Estado em "cidadãos" e aqueles "sem nacionalidade", os primeiros exerciam o direito a voto e seguridade social no entanto não eram obrigados a pagar imposto e nem participarem do serviço militar, ao contrario dos mestiços e marrons. Consequentemente, as distinções "interétnicas" também se manifestaram internamente, tanto no campo ideológico e cultural como no grau de aceitação do projeto de afirmação da nacionalidade crioulo-guianesa.

Os Galibis (Kalinas) embora sejam historicamente o grupo de indigenas que tiveram maior interação, buscaram estratégias de reconhecimento de sua identidade. Segundo Cleaver (2006) 
este grupo foi o responsável pela criação em 1982 da Federação das Organizações Autóctones da Guiana (CHALIFOUX, 1992). No entanto, a crescente presença de representantes dos Galibis na administração local (Awala e Yalimapo) mostra uma disposição em participar da construção de um projeto nacional, ao contrario de outras comunidades que tendem ao um enfrentamento e/ou distanciamento da sociedade crioula.

Os bushinenges, a exceção dos Alukus (bonis) que têm uma relação mais longa com a sociedade guianesa, apresentam um processo de integração marcado pela marginalização estatal. Entre 1986 a 1992 o Suriname passava por um momento de guerra civil marcada pela intolerância e disputa étnica (MENKE, 2004), com isso grupos minoritários como os Ndyukas, Paramakas e os Saramakas procuraram exílio em solo guianês. Estes refugiados foram abrigados em assentamentos as proximidades de Saint Laurent do Maroni, muitos nas antigas instalações dos presídios.

De acordo com Bougarel (1988) esses expatriados não foram reconhecidos pelo governo francês, e tiveram o seu direito de exercer qualquer atividade política e social dentro e fora dos campos impedidos. Com o término do conflito no Suriname, os campos foram fechados e os refugiados mandados de volta, porém muitos deles decidiram se estabelecer definitivamente na Guiana Francesa. Assim, os marrons são legalmente considerados imigrantes que necessitam das formalidades burocráticas para solicitar a cidadania francesa.

Por extensão a identidade étnica desses grupos foi muito consolidada, fundada na ideologia da marronage, ou seja, na resistência ao sistema (pos) colonial e a recusa à modernidade. Desta forma, para Cleaver (2006) bushinenges e crioulos são identidades "negras" que se distingue entre si pelo mito "fundacional", logo a integração dos marrons a sociedade guianesa representa mais uma busca por uma melhoria na qualidade de vida e/ou formalidade legal do que uma forma de aculturação.

Tais descontinuidades põem em dúvida a conformação de uma nacionalidade guianesa por meio da equivalência entre ameríndios, bushinenges e crioulos. Mais do que isso, as diferenças nos valores e nos idiomas existentes entre esses grupos étnicos e desses com os outros, indicam a existência de um "mosaico étnico" onde tais grupos coexistem, sem se misturar (CLEAVER, 2006, p. 31). Portanto, a configuração espacial da Guiana Francesa seria assinalada pelo pluralismo cultural, social e estrutural, consubstanciada por fronteiras étnicas bem delineadas.

Todavia, a realidade se mostra mais complexa devido ao aumento significativo dos casamentos mistos oficiais ou não entre indivíduos de etnias diferentes. A miscigenação é um processo historicamente inegável da sociedade da Guiana Francesa, e que nos últimos anos vem se ampliando com o crescimento dos movimentos imigratórios. Com isso, o projeto de construção da nação guianesa (crioula) convive de um lado com o sistema pos colonial francês e de outro com identidades multifacetadas.

Em resumo, o crioulo da Guiana Francesa pode ser distinguido pela oposição aos outros grupos minoritários formados por autóctones (ameríndios e marrons) e de imigrantes em sua volta. Nos dizeres de Jolivet (1990) a tarefa é bastante simples quando se coteja grupos que buscam se auto-diferenciam a todo o momento por meio de manifestações sócio-culturais e étnicas na esfera publica e privada, porém torna-se um desafio quando essas identidades estão em transito entre as fronteiras étnicas, como no caso da sociedade crioulo-guianesa.

Neste contexto, a identidade créole na Guiana Francesa é constituída nos interstícios entre o universalismo francês, os elementos da crioulidade caribenha, a força poética e política da negritude (raízes africanas), a influência da cultura dos imigrantes e a busca pela (re) valorização dos costumes autóctones. Portanto, conclui Mam Lam Fouck (2002) ela torna-se um produto de um enraizamento triplo (francesa, sul americana e africana) que são instrumentalizados em razão dos interesses em jogo.

Geografia Ensino \& Pesquisa, v. 16, n.2 p. 7 - 22, maio/ago. 2012 


\section{As identidades étnicas e suas espacialidades}

A idéia de identidade, em termos antropológicos, é produto da interação no espaço e no tempo de grupos reconhecidos como semelhantes em contraposição aos outros, neste contexto, a identidade tem sempre um caráter relacional resultado do fortalecimento das redes interpessoais subjetivas e concretas e 0 (auto) reconhecimento das diferenças.

A representação da modernidade se manifesta na assimilação do tempo e do espaço da Guiana Francesa a partir de uma padronização coagida pelo individualismo e a competitividade própria do capitalismo, que, paradoxalmente, permite as condições objetivas e imateriais para a sua contestação. Neste contexto, o caráter efêmero da vida moderna, devido o deslocamento constante, o que acaba reforçando o não enraizamento, de um lado, revela espaços de representações imediatas, que espelham a memória coletiva de grupos que não conseguem ser coagidos pela abstração espacial.

A idéia de modernidade, na concepção weberiana, tornou-se um conceito diretamente amarrado ao sentido de progresso técnico, econômico e científico, em contraposição qualquer orientação diferenciada (subjetiva e/ou tradicional) era denominada de irracional. Neste sentido, houve uma secularização dos atos individuais, bem como uma desvinculação em relação às determinadas estruturas consideradas não modernas (WEBER, 1991). A idéia de espaço moderno, então, tornou-se uma concepção de negação a tradição, a subjetividade, ou seja, rejeita qualquer tipo de alteridade.

Todavia, Habermas (1988) enxerga outra modernidade em que os sujeitos coordenam suas intervenções no espaço vivido através da ação comunicativa. A idéia funda-se no conceito de razão dialógica, fruto do diálogo e da argumentação entre agentes envolvidos em uma dada situação, o que então levaria ao surgimento de uma ação comunicativa, onde a linguagem seria a forma de se obter 0 consenso, o que se realizaria mediante as condições devidas de liberdade e de não constrangimento da negociação.

Assim, a teoria da ação comunicativa acaba por fornecer os elementos para se compreender uma "ética discursiva" que recorre à razão como fundamento, não nos moldes kantiano que defende 0 conceito de razão reflexiva fundamentado no sujeito levando a uma razão monológica, mais sim uma razão dialógica, ou melhor, uma razão comunicativa que supõem o diálogo e a interação das diferenças.

A razão comunicativa caracteriza-se, assim, como processual e é construída por meio da relação entre os indivíduos com capacidade de interpretação pessoal diante das regras sociais, mas ao mesmo tempo capazes do entendimento dialógico racional. Desta maneira seria a subjetividade convertida em intersubjetividade, definida como uma interpretação pessoal das regras conduzida ao consenso construído conjuntamente.

Giddens (2003) acrescenta que a modernidade apresenta efeitos colaterais sobre os quais não temos controle e muitas vezes não temos conhecimento, desta maneira vivemos em uma sociedade de risco. Nesta direção, a modernidade "reflexiva" é um fenômeno peculiar do mudo atual que ultrapassa a idéia de traço comum entre as sociedades. Ademais, nesta ordem "póstradicional", mesmo nas sociedades ditas mais modernas, as identidades não desaparecem e sim florescem cada vez mais.

Deste modo, o processo social de construção de identidades tem como base atributos tais como os étnicos, culturais, políticos, religiosos, simbólicos, de classe social entre outros. Para Castells (1998) existem três formas de se instituir uma identidade: 1) através da legitimação,

Geografia Ensino \& Pesquisa, v. 16, n.2 p. 7 - 22, maio/ago. 2012

Territorialidades étnicas e identidade nacional: o caso da Guiana Francesa introduzida por instituições dominantes no intuito de expandir o seu poder; 2) pela resistência, advinda de grupos sociais que têm pensamentos diferenciados; 3) com um projeto, quando se busca redefinir a sua posição dentro de uma sociedade.

A configuração espacial da Guiana Francesa traz à tona esses processos de construção de identidades étnicas, induzindo as novas formas de transformação, resistência e assimilação, isso porque a sociedade em rede está fundamentada na disjunção sistêmica entre o local e o global 
para a maioria dos indivíduos e grupos sócio-étnicos. Portanto, uma identidade de resistência pode resultar em um projeto de uma comunidade, e posteriormente em uma identidade legitimadora dentro de um determinado contexto social.

Por outro lado, a convivência estabelece uma relação dialética, criando um processo de confronto e, ao mesmo tempo, de integração, no qual tanto se afirma o interesse individual e de grupo quanto se absorve interesses universais. Nos dizeres de Brandão (1986) qualquer identidade apenas se torna uma ação estratégica de delimitação territorial arquitetado pela consciência dos sujeitos ou de um grupo no momento que estes se vêem ameaçados de alguma forma pelos outros.

Neste aspecto, a idéia de identidade não se resume a uma realidade pré-existente e, sim como um processo em constituição. Bauman (2005) esclarece que a identidade é um fenômeno construído pela humanidade, que muitas vezes esconde a condição precária e eternamente inconclusa das relações sociais. De outro lado, a identificação individual e/ou de grupo torna-se também um fator poderoso de hierarquização social, como no caso da Guiana Francesa.

Logo, a conformação identitária não é autêntica fora de um contexto antagônico, estão sempre ligados a algo que está em jogo (AGIER, 2001, p. 9). Deste modo, não existe definição de identidade em si, depende de um auto-reconhecimento e seus vínculos com os outros. A partir dessas interações é que se torna possível a permanência e/ou transformações no "pertencimento" original de cada um de nós, seja étnico, religioso, cultural, político etc.

Pollak (1992) observa que há um elemento entre essas atribuições da identidade que necessariamente escapa ao indivíduo e, por extensão, ao grupo: o outro. Nenhum indivíduo pode construir uma auto-imagem isenta de negociação, de transformação em função dos outros. A construção da identidade é um fenômeno que se produz em referência aos critérios de reconhecimento, o que se faz por meio da relação com outros. Nessa acepção, a memória coletiva e a identidade são valores disputados, designadamente, em conflitos que opõem grupos diferentes.

Por esse motivo, Bauman (2005) afirma que as nossas "identidades" não têm nenhuma solidez, são bastante negociáveis e revogáveis durante o decorrer da nossa vida. Além de que a idéia de ter uma identidade não vai ocorrer da mesma maneira em pessoas com a mesma pátria ou etnia por exemplo. A idéia de "pertencimento" é uma condição sem alternativa, ou seja, é preciso ter 0 auto-reconhecimento diante dos outros.

Isso significa que as identidades estão cada vez mais deslocadas no tempo e no espaço criando novas formas de auto-identificações, mais emaranhadas. Deste modo, os tradicionais sinais diacríticos que antes delimitavam as fronteiras territoriais, como a linguagem, vestimentas, ritos e hábitos perderam a força na modernidade. Concomitantemente, a natureza da identidade é cada vez mais "contrastiva" (OLIVEIRA, 2006), ou seja, não é um produto do isolamento, mas se manifesta através da intensificação das interações.

$\mathrm{Na}$ Guiana Francesa há cenários privilegiados desse tipo de encontros e desencontros de identidades. Nesse intermédio, os moradores acabam sempre construindo identidades múltiplas, uma vez que suas referências pertencem a mundos diferentes e conflituosos, em que suas raízes invariavelmente os ligam a sua memória coletiva e, paradoxalmente são impelidos a novos diálogos pela necessidade de readaptarem ao novo cotidiano em que vivem (HAESBAERT; SANTA BARBARA, 2001, p.49).

Ademais, as diferenças étnicas acabam sendo reveladas pela forte estratificação social. Como explica Thurmes (2006, p.10) o aspecto multiétnico desse tipo de sociedade também é um fator poderoso de geração de segregação, pois existem aqueles que tiveram negado o seu direito de escolha, pois foram rotulados arbitrariamente pelos outros. Deste modo, existem determinadas identidades que estigmatizam, humilham e descrimina o indivíduo, nesses casos a luta é pelo repúdio desses estereótipos.

Os indígenas e os bushinenges, por exemplo, são desde o período colonial grupos apontados como primitivos e selvagens, o que explicaria a estagnação econômica, política e cultural da Guiana Francesa. De acordo com Guyon (2008) os primeiros partirem desde inicio dos anos 90 para uma

Geografia Ensino \& Pesquisa, v. 16, n.2 p. 7 - 22, maio/ago. 2012

Souza, C. B. G

ISSN 2236-4994 
política de reversão dessa identidade estigmatizada, através de uma (re) apropriação da categoria ameríndia, tornando-a positiva e agregadora. Mas recentemente, os bushinenges trabalham nessa mesma direção realçando as tradições ancestrais (Africanas)

Uma situação mais abjeta vive aqueles que têm negado o direito de reivindicar uma identidade. O significado desta "subclasse" é a ausência de identificação, a negação do pertencimento, a abolição da individualidade, a exclusão do espaço discursivo de negociação (BAUMAN, 2005, p.46). Os refugiados e os clandestinos são um dos exemplos mais contundente de como é possível negar o direito a presença física e simbólica de alguns grupos dentro de um território.

Na Guiana Francesa, existe um conjunto considerável de grupos sócio-étnicos que se encaixam nesse perfil, os brasileiros "ilegais" são submetidos a atos de violência que podem ser expressos por meio de constrangimentos verbais até os abusos sexuais antes de serem expulsos (SOARES, 1995). Os refugiados surinamienses, do inicio dos anos 80 , foram impedidos de trabalhar, estudar ou exercer qualquer atividade em solo francês (BOUGAREL, 1988). Por sua vez, os haitianos são submetidos à condição de trabalho precário e, muitas vezes informal, sem garantias legais.

Trata, então de compreender a articulação entre o universalismo e as particularidades que traz a tona o grande desafio da modernidade que é evitar o recrudescimento de possíveis fragmentações de caráter identitário. De acordo com Léna e Jolivet (2000) mais do que uma tentativa comunitária de se livrar de estigmas, a emergência de particularismos visa ultrapassar determinadas barreiras que dificultam a inserção individual em sociedades cosmopolitas.

Mesmo a despeito das imprevisibilidades, Oliveira (2006) aponta que existem pontos em comuns nas diversas conformações de identidades que se auto-reconhecem como diferente em relação aos outros, inicialmente o próprio reconhecimento da identidade como expressão de sua particularidade, posteriormente a construção de espaços comuns apesar e a partir das diferenças e por fim, a busca de uma ordem moral, a "taxa de consideração" como fonte de dignidade individual e coletiva (OLIVEIRA, 2006, p. 113).

Assim, pode-se definir a identidade como uma representação imediata da corporeidade humana, o que significa uma tendência especifica de organizar as formas espaciais em conformidade com seus territórios existenciais (ELHAJJI, 2002). Com isso, nosso entorno material é a nossa imagem e ao mesmo tempo a dos outros por meio de relações estabelecidas. Em vistas disso, a "pregnância" da memória coletiva é suscetível a emergir ao primeiro plano de nossas espacialidades.

Nesse contexto, as espacialidades dos grupos étnicos da Guiana Francesa são compostas por valores distintos, enquanto alguns buscam apenas juntarem dinheiro para construir um "negócio", outros criam vínculos afetivos com o espaço. No segundo caso, a rotina é baseada na dedicação ao trabalho, na contenção de despesas e, principalmente, na persistência de uma rede social com o seu local de origem (SIMONIAM; FEREIRA, 2005). Deste modo, a memória coletiva é uma referência constante dentro dos espaços vividos.

Por outro lado, diversos grupos são estigmatizados, criando um estereotipo em relação à determinados grupos étnicos, o que nas palavras de Jolivet (1986: 402) é produto de uma separação efetivada com uma dupla base racista e nacional. Paradoxalmente, tal descriminação é algo que acaba sendo reproduzido no interior dos próprios grupos, principalmente os que compõem uma classe média, instituindo distinções de valores que repercutem nas espacialidades.

Observa-se, assim, uma relação de rejeição induzida por um etnocentrismo, o que repercute

Geografia Ensino \& Pesquisa, v. 16, n.2 p. 7 - 22, maio/ago. 2012

Territorialidades étnicas e identidade nacional: o caso da Guiana Francesa nas interações com o "outro". Isso pode ser observado na organização das manifestações culturais, nos traços comportamentais, nos pontos de encontro, na relação com a língua oficial (francês) e nas habitações. De outro lado, existe no âmbito desses espaços comuns como praças, escolas uma aproximação, principalmente em relação algumas manifestações socioculturais.

Contudo, essa adequação e relativa aceitação não significam uma integração à sociedade local, um dos traços mais marcantes dessa alteridade é o quase total desconhecimento da língua oficial (francês). Essa dificuldade tem sua origem no nível de escolaridade da maioria dos grupos 
étnicos, mas também na não necessidade de aprender o idioma para se engajar no mercado de trabalho local. Por isso, muitos por imitação vão repetindo a linguagem da rua, baseada na gíria e nas características da língua crioula.

Por outro lado o caráter transitório da imigração, com a perspectiva de voltar ao pais de origem e a racionalidade instrumentalizada que impera em toda Guiana Francesa acaba sendo um fator de não apropriação do espaço. Paradoxalmente, a conformação de uma rede social e o numero de casamentos mistos vem direcionando para outra configuração de novas espacialidades.

Assim, as espacialidades na Guiana Francesa equilibram-se principalmente na força de coesão e na solidariedade dos laços de amizade. Com isso, mesmo com a tentativa do Estado francês de impor um cotidiano baseado na artificialidade e no controle social, político e cultural, as praticas sócio-espaciais dos grupos étnicos acabam sendo constantemente reconstruída pelas diversas experiências individuais e de identidades que ali coexistem.

\section{Considerações finais}

A Guiana Francesa é uma região repleta de símbolos, insígnias e representações espaciais que designam um sistema de sinais, de códigos e de convenções ligada diretamente às identidades étnicas. De outro lado, o processo de aculturação e busca pela afirmação de uma sociedade criouloguianense contrapõe-se a etnicidade desses grupos, criando uma constante reconfiguração étnica, estabelecendo novas delimitações de suas fronteiras.

A França, adepta ao universalismo, busca no distanciamento de qualquer memória anterior (experiência empírica) a consolidação de suas leis universais. Assim, o modelo francês de integração não tolera as diferenças seja aquelas trazidas pelos imigrantes ou originarias dos povos colonizados. Para tanto, apóia-se em uma política de aculturação que tem como base um vasto patrimônio histórico, cultural, político, religioso, artístico francês que cria uma sedução estética e simbólica.

Nas antigas possessões francesas esse processo de universalismo republicano, de integridade moral constitui um verdadeiro "eufemismo" da velha política de dominação colonial, criando divisões sociais. Conforme Blanchard e Bancel (2006, p. 146) o estado francês foi substituindo a figura dos povos colonizados (ameríndios) pela dos grupos autóctones (crioulos) e de imigrantes.

Portanto, a condição de cidadão passa pela assimilação de normas e regras morais historicamente definidas pelo Estado (razão pura). Todavia, Thurmes (2006) indica que mesmo com a força da política ideológica do Estado francês voltada para não permitir a sobrevivência das diferenças, existe movimentos de resistências por toda a França Dentro deste contexto, o caso da Guiana Francesa segue esta lógica, embora de uma forma bastante peculiar, com o processo de afirmação de uma sociedade autóctone (crioulo-guianesa), e dos direitos dos imigrantes.

\section{Referências}

AGIER, Michel. Distúrbios identitarios em tempos de globalização. Mana 7 (2): 7-33, Rio de Janeiro: UFRJ, 2001.

AROUCK, Ronaldo de Camargo. Brasileiros na Guiana Francesa. Fronteiras e construções de alteridades. Belém: NAEA/UFPA, 2000. 223p.

Geografia Ensino \& Pesquisa, v. 16, n.2 p. 7 - 22, maio/ago. 2012 
BERNAND, 2001. Les identités religieuses et ethniques àl'aune de l'universalisme républicain. A propos de l'exception française. Champ Psychosomatique 2001/1, n 21, p. 133-150.

BLANCHARD, P; BANCEL, N. Culture post-colonial 1961-2006. Traces et mémoires coloniales em France. Paris : Autrement, 2005. 287p.

BOUGAREL, Sophie. Les refugiés surinamiens en Guyane. Les Cahiers d'outre-mer, Bordeaux, Octobre 1988. pp.43-50.

BRANDÃO, Carlos. Identidade e etnia: Construção da pessoa e resistência.São Paulo: Brasiliense, 1986.

CALMONT, André. Trajets socio-identitaires chez les jeunes issus de la migration haitienne en Guyane. Cuadernos interculturales, año 5, n 9, 2007, pp. 9-27.

CARDOSO, Ciro Flamarion. La Guyane Française (1715-1817): Aspects économiques et sociaux. Contribuition à l'étude dês sociétés esclavagistes d'Amérique. Petit-Bourg, Guadeloupe: Ibis rouge, 1999. 424p.

CASTELLS, Manuel. O poder da identidade. A era da informação: economia, sociedade e cultura. São Paulo: Paz e Terra, 1998

CHALIFOUX, Jean-Jacques. Ethnicité, pouvoir et développement politique chez lês Galibis de La Guyane française. Antropologie et sociétés. Vol.16. n.3 : 37-54, 1992.

CHÉRUBINI, Bernard. Interculturalité et créolisation em Guyane Française. Paris: L'Harmattan, 2002. 270p

CLEAVER Ana Julieta Teodoro. "Ni vue ni connue": a construção da nação na Guiana francesa. Dissertação de Mestrado, UnB, Brasilia, 2003.

COLOMB, Gérard. Entre ethnicité et national : a propos de la guyane. Revue socio-anthropologie, n 6, passages, CIRCLES (Centre Interdisciplinaire Récits-Cultures-Langues et Sociétés), 1999.

CORNUEL, Pascale. Guyane Française du "paradis" à l'enfer du bagne In:FERRO, Marc. Le livre noir du colonialisme. XVI-XXI siècle : de l'extermination à la repentance. Paris : Hachette, 2003. pp.275-290.

ELHAJJI, Mohammed. Memória coletiva e espacialidade étnica. Galaxia,n 4: 177-191, 2002.

GUYON, Stéphanie. Amérindiens et Noirs-marrons en Guyane Française. Les conditions sociales de retournement du stigmate. Disponivel em: http://www.unil.ch/webdav/site/ iepi/users/cplatel/public/atelier_4/Guyon.pdf. Acesso: outubro de 2008.

HABERMAS, Jurgen. Teoria de la acion comunicativa. Madrid: Taurus, 1988.

HAESBAERT, Rogério; SANTA BARBARA, M. Identidade e migração em áreas transfronteiriça. GEOgraphia, Ano III, n 5: 43-60 Rio de Janeiro, UFF, setembro de 2001.

Geografia Ensino \& Pesquisa, v. 16, n.2 p. 7 - 22, maio/ago. 2012

Territorialidades étnicas e identidade nacional: o caso da Guiana Francesa

HIDAIR, Isabelle. L'espace urbain cayennais : Champ de lutte identitaire. Second Congrés bisannuel du GIS-Réseau Amérique Latine. Rennes 15-17 Novembre 2007.

JOLIVET, Marie-José. La question créole. Essai de sociologie sur la Guyane Française. Paris : Centre ORSTOM, 1986.495p. 
KOZAKAI, T; WOLTER, Rafael P. Armadilhas do multiculturalismo: análise psicossocial da integração à francesa dos estrangeiros. Aletheia, n.26, p.11-26 jul./dez. 2007

LENA, Philippe \& JOLIVET, Marie-José. Des territoires aux identités. Autrepart (14) : 5-16, 2000.

LÉZY, Emanuel. Guyane, Guyanes: Une géographie « sauvage » de l'Orénoque à l'Amazone. Paris : Belin, 1989. 347p.

MAM LAM FOUCK, Serge. Histoire générale de La Guyane française.Guyane : Ibis Rouge, 2002. 220p.

MENKE, J. Multiethnic caribbean democracies : a comparative exploration . in : MENKE, $\mathrm{J}$. Political democracy : social democracy and the market in the caribbean. Panamaribo : Anton de kom University of Surinam, 2004. p. 163-191.

OLIVEIRA, Roberto Cardoso de. Caminhos da identidade. Ensaio sobre a etnicidade e multiculturalismo. São Paulo: Ed Unesp, 2006. 256p.

POLLAK, M. Memória e identidade social. Estudos Históricos, Rio de Janeiro, vol. 5, n. 10: 200-212, 1992.

PRICE, Richard. Maroons in Suriname and Guyane : How many and Where. New West Indian Guide vol $76 \mathrm{n} 1$ \& 2, 2002, pp. 81-88.

SIMONIAN, Ligia T. L. \& FERREIRA, Rubens da S. Trabalho e vida em terra estrangeira: o caso dos imigrantes brasileiros na Guiana Francesa. Historia revista, 10 (2): 227-253, jul/dez 2005.

SOARES, Ana Paulina Aguiar. Travessia: Analise de uma situação de passagem de passagem entre Oiapoque e Guiana francesa. Dissertação (Mestrado de Geografia humana) USP, São Paulo, 1995.

THURMES, Marion. Les metropolitans em Guyane: une intégration sociale entre individu et groupe culturel. Thèse (Doctorat de Sociologie). Université III. Montpelier, 2006.

VILLAR, Diego. Uma abordagem critica do conceito de "etnicidade" na obra de Frederick Barth. MANA 10(1): 165-192, Rio de Janeiro: UFRJ, 2004.

WEBER, Max. A ética protestante e o espírito capitalista. São Paulo: Ed Ática, 1991.

\section{Correspondência:}

Charles Benedito Gemaque Souza - Travessa Perebebui, 481, Pedreira. Belém-PA. CEP: 66083-640

E-mail: gemaque.charles@gmail.com

Recebido em 09 de agosto de 2011

Aceito para publicação em 25 de outubro de 2011.

Geografia Ensino \& Pesquisa, v. 16, n.2 p. 7 - 22, maio/ago. 2012 
